\title{
Impasse aos Desafios do uso de Smartphones em Sala de Aula: Investigação por Grupos Focais
}

\author{
Francisco Reinaldo ${ }^{1}$, Demétrio R. Magalhães ${ }^{2}$, Luis Paulo Reis ${ }^{3}$, Stefane Gaffuri ${ }^{4}$, Ademir \\ Freddo $^{5}$, Renato Hallal ${ }^{6}$
}

reinaldo@utfpr.edu.br, reno@unilestemg.br, lpreis@dsi.uminho.pt, stefanegaffuri@utfpr. edu.br, ademir.freddo@uffs.edu.br, renatohallal@utfpr.edu.br

${ }^{1}$ Departamento Acadêmico de Informática, Universidade de Tecnológica Federal do Paraná UTFPR - Campus Fco. Beltrão/PR, 85601-970, Brasil

${ }^{2}$ Escola Politécnica, Centro Universitário do Leste de Minas Gerais UnilesteMG, Cel. Fabriciano/MG, 35170056 Brasil.

3 Universidade do Minho, Escola de Engenharia, Departamento de Sistemas de Informação e LIACC -
Laboratório de Inteligência Artificial e Ciência de Computadores, Guimarães e Porto, Portugal.
${ }^{4,6}$ Departamento Acadêmico de Matemática, Universidade de Tecnológica Federal do Paraná UTFPR -
Campus Fco. Beltrão/PR, 85601-970, Brasil.

${ }^{5}$ Laboratório Interdisciplinar de Formação de Educadores (LIFE), Universidade Federal da Fronteira Sul (UFFS) - Campus Realeza/PR, CEP 89802-112, Brasil

DOI: 10.17013/risti.19.77-92

\begin{abstract}
Resumo: Este artigo discute o uso dos smartphones nas escolas e na universidade. Respeitando a Declaração de Helsinki, professores das cinco escolas do ensino médio e de uma escola de ensino superior (grupos focais) localizadas no estado de Minas Gerais, Brasil, foram entrevistados para apresentar os benefícios, limitações e resistências relativos à ampla utilização do smartphone como ferramenta da construção do saber pelo aluno em sala de aula. Referências literárias relacionadas com ensino e informática deram suporte às opiniões dos professores que foram entrevistados. Os resultados obtidos elucidam os relatórios da UNESCO, que correlacionam positivamente os anseios e medos dos professores ao lidar com este tipo de tecnologia que está em evolução numa constante curva logarítmica ascendente. Também se discutem as novas contribuições para diminuir a evasão dos alunos, conservando a integridade da visão do professor e a peculiaridade dos estudantes em sala de aula.
\end{abstract}

Palavras-chave: Ensino; Tecnologia móvel. Smartphone.

\section{Challenges to the use of Smartphones in Brazilian Classroom: Research by Focus Groups}

Abstract: This article discusses the use of smartphones in schools and university. Respecting the Declaration of Helsinki, teachers from five secondary schools and a higher education school (focus groups) in the state of Minas Gerais, Brazil, were 
interviewed to present the benefits, limitations and resistance concerning the wide use of smartphone as a knowledge construction tool by students in the classroom. Literary references related to education and informatics support the opinions of teachers who were interviewed. The results shed light on the UNESCO reports that positively correlate the anxieties and fears of teachers in dealing with this type of technology, which is evolving such as a steady upward logarithmic curve. The paper also discusses new contributions to reduce students' dropout, saving the teacher's view of the integrity and the students' characteristics in the classroom.

Keywords: Teaching; Mobile technology. Smartphone.

\section{Introdução}

As novas gerações de estudantes pressionam a academia para o uso do smartphone em sala de aula. Em 2011, a Pesquisa Nacional por Amostra de Domicílios levantou dados sobre o uso de celular e descobriu que pessoas acima de 10 anos idade foram estimadas em 115 milhões, o que correspondia a 69,1\% da população do país (IBGE, 2013). Educadores instrucionalistas sentem-se intimidados com as mudanças propostas pela nova tecnologia. A proposta de aceite envolve remodelar os papéis de ensinoaprendizagem; consequentemente implicando em novos resultados. A tendência ótima seria o educador abandonar seu papel no ensino de "estar presente" e agir de modo a "ser presente". Também o papel do aluno seria direcionado a desenvolver o seu modelo objeto de aprendizagem. O desafio do educador está em acreditar que o aluno consiga deixar a confortável posição de ouvinte para construtor de si próprio.

Educadores apresentam smartphones como algo que estimula a indisciplinariedade e a diminuição da capacidade de concentração do aluno em sala de aula (Serra, 2014). Ao interpretá-lo erroneamente como uma ameaça à autoridade do educador, muitas escolas não fazem grandes esforços para adaptá-lo em sua estrutura educacional de práticas pedagógicas. A sociedade, embora simpatizante da tecnologia, não o define claramente como algo a ser considerado importante, mas o reconhece como uma incógnita a ser resolvida pela escola. Neste impasse, este aparato tecnológico estremece as bases mais conservadoras.

As escolas ainda utilizam o legado deixado pelos computadores desktop como representantes legítimos da Tecnologia de Informação e Comunicação (TIC), seja na modalidade presencial ou à distância. Infelizmente, a aplicação de estratégias didáticopedagógicas em laboratórios específicos com desktops é restritiva a possibilidades de acesso. Por ser a escola uma instituição formadora da sociedade, a antevisão dos smartphones como recurso em práticas educacionais conflitua com os interesses dos alunos e se desmotivam. Acredita-se que uma das razões para o educador preservar o estilo behaviourista de Jean Piaget (1976) que voga numa tentativa estocástica de falso equilíbrio das estruturas cognitivas pode estar no medo pela perda da autoridade exercida sobre o aluno, tendo o conhecimento como moeda de troca, um claro contraponto aos ensinamentos de Lev Vygotsky (Koll, 2010).

Quando se observa o uso do smartphone em sala de aula, curiosamente percebe-se que os alunos buscam por aplicativos, gratuitos ou não, que transformem as particularidades teóricas do plano de ensino do professor em objetos animados e de interação. Se a informática é indubitavelmente um recurso na educação, a substituição dos conteúdos 
lineares por objetos dinâmicos de aprendizagem prepararia os estudantes para resolver problemas complexos e com alto nível de abstração? Percebe-se que o uso das TICs, sobre "exclusão digital" e "analfabetismo digital” (Oliveira \& Júnior, 2013) não está coerente. Para Vygotsky (Koll, 2010), o aluno deve atuar como protagonista na construção do conhecimento, mas nunca desamparado.

Para elucidar se o uso do smartphone na sala de aula é prejudicial, utilizou-se da entrevista como método de investigação qualitativa para coleta de dados (Bauer \& Gaskell, 2002; Vázquez et al., 2016) por meio da formação de grupos focais com roteiro de questões predeterminadas por entrevista semiaberta e verificação cruzada. Respeitando a Declaração de Helsinki, foram entrevistados, de maneira aleatória, 36 professores em idade de 23 a 45 anos, sem viés ao uso de tecnologia em sala de aula, possuindo entre 3 e 10 anos de magistério, pertencendo as classes socioeconômicas B e C, em 6 instituições educacionais não rurais, sendo 5 escolas públicas de ensino médio e uma instituição de ensino superior, ambos na região do Vale do Aço, estado de Minas Gerais/ Brasil. Uma tabela de área de conhecimentos (CAPES \& CNPq, 2012) foi utilizada para balizar as disciplinas dos professores do ensino médio a dos professores da graduação, comtemplando 7 das 9 áreas de conhecimentos. As salas de aulas destes professores são compostas por alunos em sua maioria pertencentes às classes socioeconômicas $\mathrm{B}$ e $\mathrm{C}$. Os professores foram distribuídos em 6 grupos focais ( 6 professores em cada grupo), sendo 22 mulheres e 14 homens. Cada grupo foi constituído por homens e mulheres, sendo que o próprio pesquisador orientou a pesquisa em duas sessões de duas horas/aula por grupo, obtendo um estudo total de 72 horas.

O objetivo deste artigo é compreender, avaliar e discutir as vantagens e limitações do uso dos smartphones como recurso ferramental durante o processo de ensino-aprendizagem do estudante em sala de aula. Além disso, fornecer fundamentação teórica e orientação prática do uso dos smartphones em um ambiente estudantil. Assim, procurou-se buscar imparcialidade e relevância acadêmica, contribuindo com ideias para outros pesquisadores e tutores nessa área. A seção 2 fundamenta a utilização de smartphones no processo de ensino-aprendizagem associada ao trabalho da pesquisa qualitativa, mais especificamente resultados obtidos na pesquisa realizada com os professores, bem como a aplicação destes resultados na diminuição da evasão, aumento da motivação dos alunos e também da aplicação das tecnologias na educação. As considerações finais são apresentadas na seção 3 .

\section{Uso dos Smartphones na Escola}

A sociedade contemporânea vivencia a era do acesso a informação pelo uso de diferentes aparatos computacionais conectados a internet ou entre si. Tais aparatos, intitulados smartphones, oferecem interatividade, robustez, rápido acesso e alto desempenho computacional. Em face da natural utilização do smartphone, questionou se existem políticas institucionais preocupadas em oferecer a correta utilização deste ferramental para ensino-aprendizagem. Até o momento, IBGE, UNESCO e tampouco os professores do grupo tem estatísticas atualizadas sobre escolas preocupadas em inserir smartphones como instrumentos de aprendizagem. Face a evolução tecnológica diária confrontada, poucos educadores se atrevem a prever algo. 
Antes de iniciar a atividade de entrevistas, procurou-se montar um panorama dos participantes para traçar um perfil de perguntas que guiasse as entrevistas/discussões sobre o tema proposto. A Figura 1 apresenta um levantamento de perfis dos participantes condensados em um plano de observação das classes socioeconômicas B e C com suas respetivas áreas de conhecimento da CAPES, cujos professores formaram a maioria. Para cada área de conhecimento (disciplina), contemplaram as categorias (a) idade média dos participantes, (b) graus de conhecimento/aptidão com o dispositivo smartphone, (c) anos de magistério, e (d) conteúdo programático escolar que poderia estar relacionado aos aplicativos do dispositivo.

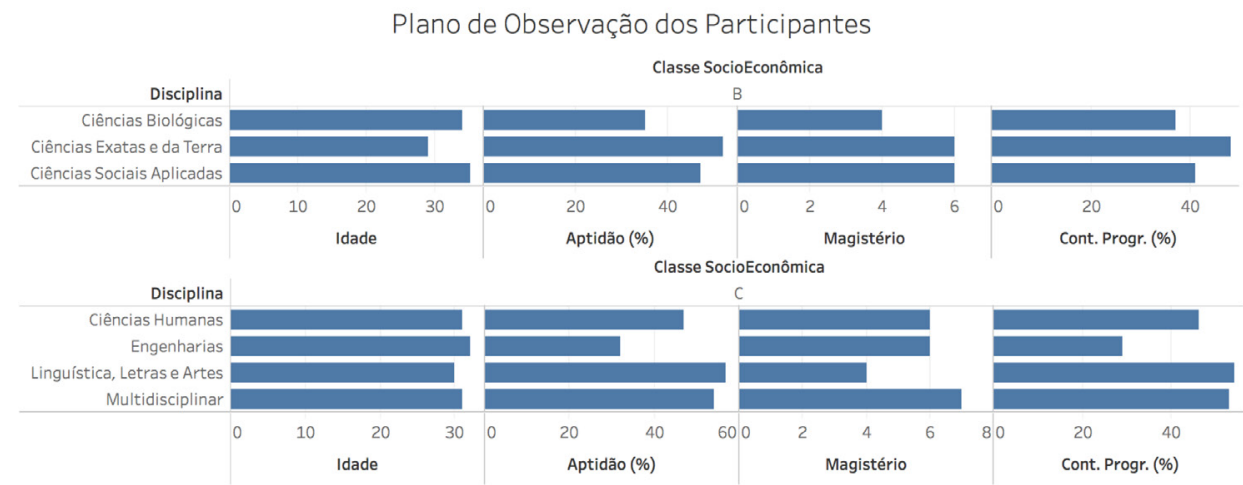

Figura 1 - Identificação global dos participantes da pesquisa.

A figura acima apresenta que professores da classe socioeconómica C estão mais aptos e sugestivos a serem inseridos no processo de socialização do uso dos smartphones nas escolas, apesar da maior idade e tempo de magistério. Vale ressaltar que o maior o tempo de magistério aparenta não se tornar um obstáculo para revisão das crenças dos projetos didático-pedagógicos de acompanhamento. Destes professores, esperam-se estratégias que contemplem ajustes nas políticas institucionais e nos métodos de aprendizagem voltados a obter o melhor dos smartphones em sala de aula.

\subsection{Porque Optar por Smartphones}

Smartphones substituem custosos laboratórios de informática, uma economia significativa para as escolas. Em contrapartida, o investimento em internet, e-books e aplicativos homologados para uso pelos alunos em sala de aula seria uma mais valia. Um smartphone oferece mais acesso a recursos literários gratuitos se comparado a completa e dispendiosa enciclopédia Britânica ou uma razoável biblioteca escolar com mais de 2000 obras físicas. Quando conectado via Google Books (Google, 2015), o acesso aos recursos literários pode chegar a mais de 210 milhões de obras em mais de 105 idiomas. Por ser de uma realidade bastante difundida, treinamento especializado para uso de smartphone não é necessário, em contraponto aos desktops. Inúmeros aplicativos categorizados em diferentes áreas do conhecimento são gratuitos e extremamente intuitivos. Os usuários de smartphones são os mais interessados em manter-se atualizados. 
Projetado para ter custos mais baixos em relação aos laptops ou desktops, adquirir um smartphone oferece a vantagem básica de uso de aplicativos educacionais gratuitos. Independente do sistema operacional, mais de dois milhões de aplicativos são gratuitos. Sabe-se que quantidade de aplicativos disponíveis não implica em qualidade, mas se 5\% satisfizerem as necessidades dos professores, assim se alcançaria uma amostra de 100 mil aplicativos abrangendo diferentes áreas do conhecimento.

"Não podemos ignorar o celular, ele está em todo lugar. Sou contra a proibição do uso, pois a regra acaba sendo burlada. Será que em vez de proibir, não é melhor acolhê-lo como ferramenta educativa? Já existem diversos aplicativos voltados para a educação especial, a alfabetização e o ensino da matemática, por exemplo.”, comenta Maria Rebeca Otero Gomes, UNESCO (West \& Vosloo, 2013)

Alunos optam por smartphones, pois tem a disposição um tutor brando e paciente, que não se queixa, não grita e não o castiga em caso de erros recorrentes. Embora alguns aplicativos possuam inteligência emocional codificada em seus núcleos computacionais, certamente as demonstrações de cansaço, irritação e impaciência não foram implementadas. Em seu trabalho, Reinaldo et al. (2009) apresenta que a inteligência, em se tratando de cognição por retroação, pode ser replicada a dispositivos computacionais a ponto de apresentar o momento exato em que a resolução do problema pelo aluno teve um desvio do padrão. Por exemplo, a cognição do professor pode ser replicada/transferida computacionalmente por sistema especialista em tutoria inteligente a fim de explicar por software de maneira pedagógica ao aluno o porquê de seu erro. Há uma preocupação impar de como evidenciar os erros nas diferentes fases de resolução do problema sem desestimular o aluno - um comportamento considerado aceitável e comum dentro do processo de ensino-aprendizagem da tutoria inteligente (Leite et al., 2015).

Smartphones sãoaceitos comoagentes revolucionários etransformadores dessa sociedade contemporânea. Também oferecem a singularidade ao seu utilizador, pois proporcionam acesso à informação de maneira facilitada e gratuita, além da portabilidade. Quando se questionou aos diferentes grupos de professores se a dificuldade de aprendizagem dos seus alunos no manuseio do aparato é aparente, a resposta mais votada entre os professores foi: "A impressão que se tem é que crianças e jovens não sentem dificuldades para manusear qualquer tipo de smartphone ou aplicativo, já nasceram sabendo!”, seja para aplicativos acadêmicos, seja na vida cotidiana.

As TICs revelam novas e motivantes perspetivas para o ensino e se permite migrar do "novo contexto social" para o "tecnológico contexto social", onde o termo novo foi absorvido pelo termo tecnológico e isto é indiscutível. A inserção de TICs como recursos pedagógicos permite resgatar alguma esperança a muitos professores e alunos insatisfeitos com as aulas e ferramentas educacionais tradicionais. Projetos escolares desenvolvidos por empresas, cita-se Apple(C) (O'Connell, Freed, Rothberg, \& Carl and Ruth Shapiro, 2010) e Google(C) (2015), oferecem novos olhares sobre a tecnologia móvel para envolver alunos com necessidades especiais ou com défices de aprendizagem durante as atividades em sala. No Brasil, a escola sofre pressão da opinião pública, do comércio e da propaganda que apregoam o uso da informática como algo urgentíssimo. 
Durante as sessões de entrevistas com professores, o termo tecnológico foi identificado como variável independente, indissociável e contendo características dinâmicas. Inserida na fórmula da educação contemporânea, a variável independente afeta de maneira efetiva e intrínseca o processo fundamental de reflexão sobre o estudo e a obtenção da informação. A tecnologia modela novas profissões, citam-se os emergentes cursos de graduação em Licenciatura em Informática. Embora muitas instituições de ensino ainda resistam a este tecnológico contexto social, os professores participantes da pesquisa das seis instituições viram-se envolvidos, muitas vezes sem perceber que os levará, de uma forma ou outra, à sua absorção.

"Sabemos que smartphones tem aplicativos nos oferecem a possibilidade de bolso para monitorar os alunos, guardando o passo-a-passo da resolução da atividade proposta. Com isso podemos interferir no exato momento que se perderam e auxilia-los para atingir condições de aprendizagem e maturidade próximas ao ideal." Pensamentos de um colegiado de matemática (Exatas) do $9^{\circ}$ ano.

Um curso ou disciplina que utiliza smartphones pode mesclar teorias de aprendizagem (Reinaldo, Camacho, \& Reis, 2010), dependendo do problema educacional proposto. Inúmeros aplicativos gratuitos ou pagos, pertencentes a diferentes áreas de conhecimento, permitem que se crie e manipule ambientes de ensino-aprendizagem. De acordo com Filatro (2010) são três as ferramentas de suporte para implementar as abordagens pedagógicas/andragógicas: (a) ferramentas de autoria (Leite et al., 2015), que permitem o fácil desenvolvimento de tutoriais, ajudando educadores e alunos na construção de softwares com muita facilidade e agilidade, pois permite instigar a criatividade multidisciplinar na construção de softwares sem precisar de muito conhecimento de informática, (b) ambientes tutoriais (Neri De Souza, Neri De Souza, Alarcão, \& Moreira, 2015), que permitem a interação do aluno com o objeto do conhecimento à medida que o aluno interage no software, permitindo o desenvolvimento de projetos individuais ou coletivos e (c) softwares educativos tipo aplicativo (Silva, Leão, \& de Souza, 2015), que são programas de uso geral em que a aprendizagem e o formato de ensino em computação em nuvens são muito eficazes. Além disso, usam da tecnologia de design responsivo para reorganizar os conteúdos de acordo com o tamanho da tela do smartphone.

Durante as entrevistas, os professores foram unânimes em afirmar que qualquer recurso computacional disponível na palma das mãos do aluno não pode ser confundido como tábua da salvação durante a delicada tarefa de educar. Vale salientar que o caminho para a conceção do conhecimento inovador deve ser constantemente renovado.

\subsection{Vantagens do Uso dos Smartphones na Escola}

Unesco (West \& Vosloo, 2013) apresenta em seu guia "Diretrizes de políticas para a aprendizagem móvel”, trabalhos onde a tecnologia móvel pode ser benéfica dentro e fora da sala de aula, a influenciar um novo modelo de ensino, reajustando o conteúdo programático a ser ensinado, o lugar de pesquisa/ação e de que maneira a aprendizagem deve ocorrer para cada aluno. Embora, a popularização dos smartphones esteja em um estágio experimental entre os professores, para os alunos está em franca ascensão e seu uso efetivo acompanha esta evolução. 
Quando indagados sobre os alunos terem acesso ao referencial teórico das disciplinas para estudo por smartphone, a resposta dos professores foi de comum acordo: “...o acesso à literatura escolar por smartphones teria maior aceitação por parte dos alunos, pois eles o usam constantemente...”. O uso racional desta tecnologia, combinando ensino e aprendizagem, pode resolver diversos problemas educacionais tradicionais. Embora alguns professores da linha menos conservacionista manifestaram preocupação sobre o local e tempo de utilização dos smartphones, a maioria dos professores partilharam a informação de que as vantagens estão essencialmente relacionadas ao bom planeamento do conteúdo programático com os tipos corretos de aplicativos. Concluíram que esta preocupação era irrelevante e responderam que “...local e tempo máximo de uso merecem tanta preocupação quanto o uso de lápis, borracha e compasso numa aula de desenho técnico.”

Dentre as atividades permitidas em sala pelo uso do smartphone, os professores destacaram (a) processadores de textos, (b) gerenciadores de bases de dados e imagens, (c) planilhas eletrônicas, (d) pacotes estatísticos, (e) processadores gráficos, (f) editores de músicas e de imagens, entre outros. A principal vantagem considerada está no reflexivo auxílio instantâneo oferecido aos alunos, não influenciando, entretanto, de maneira direta no processo de ensino-aprendizagem, pelo fato de que essas ferramentas não foram criadas com objetivos educacionais.

Através das sessões de investigação com os grupos focais, também foi possível levantar as possíveis atividades permitidas em sala pelo uso do smartphone. É interessante mencionar que o início do processo foi conturbado, não havendo consenso entre professores da área de humanas e exatas. Contudo, os trabalhos de Sternberg e Grigorenko (2003) oportunizaram sistematizar as respostas dos professores em 14 tópicos. Abaixo, o planeamento de competências e habilidades, sem desarmonizar com os conteúdos programáticos e as áreas de conhecimento destes professores são:

1. Analisar a produção gramatical por e-books interativos, jogos de palavras e ferramentas de escrita;

2. Analisar a pronúncia em vários idiomas por aplicativos capazes de reconhecer a pronúncia e sugerir a pronúncia correta no idioma nativo;

3. Reconhecer, desenhar e dimensionar objetos no espaço;

4. Identificar manifestações de melodias e compor notas musicais por instrumentos em aplicativos;

5. Sintetizar revistas, livros, dicionários, atlas e enciclopédias interativas sobre vários assuntos sem interromper a linha de raciocínio em pesquisa;

6. Elaborar estratégias que promovam a auto-organização dentro e fora das escolas;

7. Sintetizar palestras e vídeos de especialistas em eventos de congresso, avaliandoos pelos depoimentos de outros ouvintes;

8. Sintetizar simulados de provas e concursos resolvidos para melhor fixar os conteúdos;

9. Aprofundar estudos religiosos, personalizar e compartilhar experiências de leitura;

10. Dimensionar espaço de armazenamento digital suficiente para depositar, acessar e compartilhar recursos educacionais digitais; 
11. Interpretar a saúde por sistemas inteligentes de diagnósticos que aprendem com as informações submetidas e se integram aos de atividade física;

12. Identificar e avaliar os serviços técnicos e de suporte confiáveis pelos depoimentos de seus utilizadores;

13. Conhecer mapas e interpretar a cartografia;

14. Comparar transportes públicos ou privados sintetizar seus dados, planejar e traçar as melhores rotas a fim de otimizar tempo de deslocamento.

Assim, a abordagem instrutiva que apresenta o professor como detentor do conhecimento seria substituída por aquele profissional que ensina por meio de um canal bidirecional de comunicação com interação iterativa, ou seja, repetitiva. Isto enlaça o professor a fazer parte na construção do conhecimento do aluno, diagnosticando-o pelo processo de formação continuada na autoavaliação.

A Interatividade, sendo tratada como fator único à disseminação continuada, possibilitaria esta abertura de comunicação com reciprocidade de informação. Este diferencial, não permite que o aluno esteja desamparado, pois está voltado à individualidade de cada participante. Por outro lado, o instrutor-professor interage na construção do saber do aluno. Por ser um processo supervisionado com controle recorrente, a evolução intelectual do aluno acontece de maneira mais rápida, tendo em vista que todo o processo é dirigido a este fim. Por conseguinte, a avaliação do aluno também deve ser recorrente e acontecer de forma gradativa e ininterrupta, apresentando de perto os acertos e falhas produzidos em todas as fases da elaboração do conhecimento. Alunos e professores apresentam-se como coparticipantes nesta construção do conhecimento plástico, mas o professor é o supervisor da aprendizagem, até um certo grau que lhe compete ir. Instrucionalmente, o aluno é exposto ao conhecimento e ao processo de avaliação recorrente e ininterrupta que é limitado aos moldes que mensuram o conhecimento construído naquela fase de amadurecimento e absorção.

Os tópicos para o planeamento de competências e habilidades acima citados foram obtidos na primeira sessão com os professores. Percebeu-se que somente os professores que dominam sua disciplina e usam a tecnologia foram capazes refletir sobre as evidências em sala e apontar sete vantagens em relação ao uso dos smartphones, as quais são enumeradas a seguir:

1. Possibilita um tratamento individualizado conforme o ritmo e a capacidade do estudante: ao utilizar o aplicativo, validado pelo professor, o aluno reconhece suas características individuais e avança no conteúdo abordado. As características individuais abordadas são grau de inteligência, conhecimento prévio do assunto, capacidade de assimilação, manifestação de seu temperamento e caráter, entre outros. Isto se fundamenta na obra de Bossuet (1985) onde o modelo tradicional de educação não possibilita levar em consideração as características individuais de cada aluno, pelo simples fato de que o professor não detém condições de atender individualmente os alunos;

2. Cria ambientes de aprendizagem rápidos, atraentes e gratificantes: com o advento da gamificação (Falcão, Leite, \& Tenório, 2014), os aplicativos educativos estão se tornando cada vez mais atraentes aos alunos, contando com recursos de imagens, sons, textos, gráficos e diagramas e bônus por atividade concluída. Estes aplicativos tornam a aprendizagem gratificante com o alto grau de interatividade a permitir simulações de fenômenos químicos, físicos e naturais; 
3. Propicia eficiência no ensino de crianças que não conseguiram aprender com os métodos tradicionais de educação: o smartphone torna-se eficiente pelo interesse que desperta nas crianças - elas têm uma forte identificação com o futuro - e a sua utilização gera uma forte excitação. O smartphone atinge mais alunos e oferece uma estratégia adicional no ensino com o uso dos Recursos Educacionais Abertos (Rossini \& Gonzalez, 2012);

4. Facilita ao aluno a busca de informações: o baixo tempo de resposta e a vantagem da animação têm o seu verdadeiro poder de atração. Assim, o aluno é conduzido por um diálogo que o envolve mais profundamente em relação ao tópico do livro físico;

5. Mantém o aluno mais ativo nas atividades escolares, possibilitando mudanças de atitude em relação ao erro, à investigação e à atividade de solução de problemas: quando o software educativo é de boa qualidade, incluindo gráficos e sons, torna-se fácil envolver toda a classe, inclusive os alunos mais dispersivos;

6. Acompanha as aptidões emergentes dos alunos: a interatividade e a cumplicidade entre aluno e smartphone que emerge durante o uso do aplicativo educativo possibilita ao aluno avançar dentro do conteúdo abordado pelo aplicativo, conforme seu ritmo e sua vontade cria um ambiente de aprendizado único;

7. Torna-se um laboratório experimental de infinitos recursos à aprendizagem exploratória: a diversidade de aplicações que podem ser adquiridas e testadas através dos smartphones faz com que se implemente sem o aluno correr riscos. Os professores devem avaliar todas as experiências possíveis, visando objetivos de ensino.

\subsection{Limitações do Uso dos Smartphones na Escola}

Os smartphones não solucionarão certamente todos os problemas do ensino. Eles podem muitas vezes não clarificar o desejo do professor, mesmo com bons aplicativos, interfaces atrativas e conteúdos bem elaborados. Durante a segunda sessão, alguns professores apontaram seus pensamentos e desvantagens em relação ao uso dos smartphones, as quais estão relacionadas a seguir:

1. Diminui as habilidades de cálculo: seu maior atrativo está na facilidade e a grande capacidade computacional para executar e armazenar cálculos numéricos. Alguns educadores sentem-se temerosos quanto ao seu uso, pois entendem que os alunos não desejarão desenvolver cálculos mental ou manualmente;

2. Não tornam, como num passe de mágica, aulas mais coerentes que foram mal elaboradas: a boa utilização dos recursos educacionais digitais e os objetivos a serem alcançados devem ser definidos pelos professores. Os softwares educativos, por melhores que sejam, não são os principais responsáveis por uma boa aula. Professores da área de humanas disseram que “...os professores têm muito mais capacidade de extrair e alcançar objetivos de ensino do que um programa holístico". Contudo, os professores reconhecem que os alunos se desdobram em redes sociais e se perdem no mundo virtual para buscar melhores exemplos em face de aulas comuns;

3. Não possibilitam que as atividades na classe se tornam permanentemente produtivas: os professores devem decidir como, quando e de que forma estes aplicativos educativos se adaptam as necessidades curriculares e oferecer-lhes um caminho adicional para explorar novas ideias e informações; 
4. Não diminui as diferenças entre as classes sociais: no Brasil, em especial, as diferenças entre as classes sociais são muito acentuadas. As escolas das elites têm recurso financeiro disponível para implantar modernos laboratórios de computação enquanto que as escolas mais pobres, principalmente as da rede pública de ensino, não conseguem ter acesso a esta tecnologia, tornando as diferenças sociais, encontradas em nosso país, ainda maiores. Embora, já se acompanha uma redução na diferença entre classes pelo uso dos smartphones, alguns professores preferem ser neutros, utilizando quadro e giz;

5. Não diminui a dispersão de concentração dos alunos pelo acesso a redes sociais: embora as redes sociais apresentem inúmeros atrativos, os educadores desta categoria acreditam que os alunos do ensino médio têm dificuldades em classificar as notícias impressionantes das notícias de conteúdo.

Abaixo, Cysneiros proferiu uma frase que se mantem atual no ensino público:

... se falta até giz na escola pública, para que se pensar em computadores? ... A escola particular de boa qualidade vem utilizando, há algum tempo novas tecnologias, salientando-se o uso de vídeo, o ensino introdutório de informática e até mesmo o uso do computador como auxiliar do professor, representando um elemento mais de discriminação entre a escola do povo e aquela das elites. (Cysneiros, 1990, p. 27)

Com a dificuldade em estimular o aluno com o método instrucionalista, muitos professores se apoiam em limitações, responsabilizando o próprio método - um paradoxo conveniente. Vale ressaltar que, por exemplo, é possível contornar o problema da posse e acesso ao smartphone se ocorrerem atividades em grupo.

\subsection{Resistências ao Uso dos Smartphones nas Escolas}

Para Papert (1985), “... a escola é um notável exemplo de uma área que não acompanhou o espantoso progresso de ciência e da tecnologia”. Embora a citação recorde as dificuldades encontradas naquela época, houveram algumas mudanças oportunas na educação (Carvalho, 2015). Todavia a escola tem o dever de preparar os jovens para utilizar e conviver com a tecnologia, como voga a Paidéia. Os smartphones fazem parte deste processo. Para que sejam introduzidos nas salas de aula, sem que haja temerosidade por parte dos educadores e professores, faz-se necessária uma preparação cuidadosa, que deve ser formulada e discutida entre todos.

A utilização da informática e da computabilidade pelas TICs na educação está relativamente ociosa, devido aos receios e preconceitos dos educadores. Durante as sessões, alguns professores se sentiram assustados quanto à proposta do uso destes dispositivos "desconhecidos" e foram enfaticamente contra. Muitos educadores insistem em acreditar que qualquer ferramenta que chame a atenção dos alunos possa então substituí-los - síndrome Teoria da Substituição - expressão cunhada por Tikhomirov et al. (2015). Para estes professores a reorganização de papéis fere seus princípios conservadores e não houve consenso sobre tornar o smartphone um instrumento sócio histórico e formador em substituição do quadro verde e giz.

Entre os educadores há duas correntes distintas: os conservadores e os inovadores. Os conservadores sentem-se pressionados e impõem sempre algum tipo de resistência 
as mudanças. Citam impedimentos a mudanças na educação, como custos, políticas, o imenso poder dos interesses investidos pelos burocratas de escola ou a carência de pesquisas científicas sobre novas formas de aprendizagem. Acreditam que os dispositivos computacionais não passam de uma tecnologia discrepante e sofisticada, que não os auxiliaria a solucionar os problemas educacionais. Felizmente, os professores inovadores revertem a situação apresentando evidências positivas para elaborar ambientes que trazem ótimos resultados educacionais, contrariando, muitas vezes, a filosofia educacional de legado proposta pelas suas instituições de ensino.

A resistência às mudanças deve ser enfrentada com inteligência, (a) fazendo com que o smartphone não seja o resultado de uma escolha imposta do alto escalão ou por alguém tecnicamente mais preparado, mas uma escolha ponderada por necessidade intrínseca de se avançar o conteúdo, decidida em reuniões de colegiado e núcleos docentes estruturantes, (b) evitando considerar o smartphone como máquina que tudo faz, nunca erra. Ele deve ter um lugar na aula, como um compasso, lápis e borracha, e seu uso deve ser estimulado nos limites aconselháveis, nunca além, (c) evitando considerá-lo como substituto do professor e (d) aceitando que não precisa ser especialista em hardware, software ou telecomunicações para trabalhar com o smartphone.

Os professores que se opõe a mudanças, passado o impacto inicial, compreenderam que os recursos tecnológicos, se utilizados de maneira a esclarecer o conteúdo abrangido em sala servirá como ferramenta de suporte ao ensino do aluno, não os deixam esquecidos ou ultrapassados, e serão lembrados pelos alunos como desbravadores de um universo pouco explorado e que preza pela velocidade da informação.

Toda a tecnologia introduzida no âmbito da educação não pode encarar a educação como simples material didático complementar e sofrer um tratamento tecnológico. Pelo contrário, é a tecnologia que deve sofrer um tratamento educacional.

\subsection{Atualização dos Professores e a Telemática}

A pouca familiaridade com a tecnologia pode ser um dos problemas enfrentados pelos professores. Considerando que o desenvolvimento da telemática abriu possibilidades às novas formas de fusão entre tecnologia, avanços na informática e educação, e que a tecnologiaéuma condição sinequa non para ensino extra-aula, oprofessor devese perceber e acreditar como agente histórico de transformações do aluno. Portanto, é fundamental que o professor e a equipe escolar em que ele está inserido tenha conhecimento sobre as possibilidades dos recursos tecnológicos e incorporação da telemática aos processos educacionais, para utilizá-las como instrumento de aprendizagem.

Durante as entrevistas, todos professores confessaram que “...estamos um pouco receosos...” diante daquilo que obtiveram pouco ou nenhum estudo técnico em sua formação acadêmica. É preciso que, ao introduzir os recursos informáticos nas escolas pela primeira vez, seja considerado a formação ou a atualização dos docentes. Isto os permite elaborar métodos de ensino para inserir e aproveitar esta nova tecnologia. Com o advento da micro e nano informática e TICs, o acesso aos smartphones popularizouse. As pessoas, mesmo sem conhecimentos específicos, passaram a utilizar este recurso. Atualmente, existem inúmeros aplicativos disponíveis de fácil utilização, de modo que nenhum professor deve sentir-se intimidado ou receoso pela tecnologia. 
Neste contexto, a atualização dos professores obedece as regras da teoria geral dos sistemas (TGS), que contém em seu sistema as características da interatividade quando se diz que a troca de energia afeta seus sistemas-membros vizinhos (ou alunos, colegas e sociedade) de forma gradativa, consoante o fator interno construído, podendo evoluirse dentro deste processo robusto. Para a TIC, este esquema de aprendizagem, também abrangido pela TGS, obedece naturalmente um processo social de um curso com estratégias metodológicas que indicam a estrutura básica do seu conteúdo programático, a dinâmica a ser adotada e a descrição dos métodos de avaliação.

Portanto, o uso de aplicativos homologados pelo colegiado e o uso de certos recursos didáticos tais como, a distribuição de tempo, de espaço, a interatividade, o local e a definição de um critério de avaliação devem ser trabalhados para a elaboração do conteúdo programático que depende das particularidades dos alunos, sendo este o objeto principal do professor. Assim, o desenvolvimento que busca a prática do aluno com a supervisão "ser presente" do docente deve estar voltado às interrelações interativas e iterativas entre seus pares. Isso implica a elaboração de uma comunidade virtual de aprendizagem e a atribuição de um tutor, podendo ser o tutor aquele aluno que melhor se destacar nas atividades sugeridas. Ferramentas como Telegram $^{\odot}$ permitem estimular outros alunos para criação de grupos, chats e apoio em tempo-real, pois é importante face a abordagem impar de conteúdos específicos de aprendizagem.

Os professores delinearam alguns objetivos primários para a atualização em sua formação, tais como (a) verificar a introdução da informática na escola, (b) replanear os objetivos, os métodos e os conteúdos de sala e mesclar com as experiências tecnológicas dos alunos para implementar novos métodos de avaliação e (c) proporcionar aos professores a capacitação técnica elementar, sem querer formar especialistas.

A informática é um dos ramos da atividade humana que mais evolui atualmente. A dificuldade apontada pelos professores está em “... sair de sua rotina quadro e giz, para uma constante atualização...”. Para o professor - pedagogo ou andragogo - a utilização de um dispositivo computacional deve resultar de uma escolha baseada no público alvo e no conhecimento das possibilidades oferecidas pelo artefacto. Todos os educadores foram unânimes em dizer "O primeiro passo na atualização da educação deve ser dado na área da informática.” e “... é preciso que se tenha um conhecimento mínimo do que é a informática, do que ela é capaz de fazer e quais são as suas limitações, senão corre-se o risco de esperar que o computador realize coisas totalmente impossíveis, e aí vem a frustração.”

A atualização pode ser realizada através de cursos de formação presencial ou à distância, leitura de revistas elivros de informática. Também as experiências já realizadas, inclusive as estrangeiras, devem ser analisadas. O professor deve, a partir de experiências já realizadas, iniciar apontamentos e experimentações próprias, avançar em seus objetivos pedagógicos e avaliar os seus resultados.

Os professores apontaram algumas sugestões para, inicialmente, ajudar seus colegas a desmistificar o uso do smartphone, tais como (a) familiarizar-se com estratégias de interação (gamificação) em alguma atividade, (b) utilizar-se de um determinado aplicativo em uma aula e que este sirva como interdisciplinar, (c) não apresentar a solução aos alunos de imediato - deixar que eles mesmos a descubram e (d) dar aos 
alunos a oportunidade para trabalhar individualmente ou em grupo e experimentar os diversos recursos oferecidos pelo aplicativo.

A desmistificação do smartphone se distingue por três características. A primeira não solicita prévio conhecimento do computador desktop ou laptop, pois já não é mais um instrumento inédito, tendo inúmeras aplicações didáticas já conhecidas e validadas. A segunda apresenta-o como um instrumento potente, capaz de satisfazer as exigências mais variadas. Por fim, a terceira cita-o como um instrumento disponível a ser preenchido por conteúdos diferentes e capaz de estimular novas ideias.

Apresentadas estas três características, alguns professores se propuseram explorar suas próprias fraquezas, envolvendo o smartphone como ferramenta para aplicar o tema "pensamento computacional” em sala de aula. Passado o medo inicial da introdução dos smartphones nas aulas, eles podem avaliar e colocar em prática suas ideias e realizar novas experiências, valendo-se de um recurso poderoso e com muitas possibilidades de uso. Os professores devem ser capazes de avaliar estes recursos e decidir os que melhor se aplicam a sua realidade e se encaixam dentro do seu projeto pedagógico.

\section{Consideração Finais}

As TICs influenciam diretamente os métodos educacionais pela adição de recursos educacionais digitais que implicam em repensar o ensino, a aquisição e transferência do conhecimento e o processo ensino-aprendizagem para uma compatibilidade construtiva socio-interacionalista, na qual os alunos criam, exploram, e integram conhecimento. Repensar o ambiente educacional e seu processo de aprendizagem com smartphones a favor do ensino e educação é uma tarefa politico-pedagógica.

Smartphones não devem ser vistos como os "salvadores" do ensino. Contudo, devem ser utilizados racionalmente visando a modernização e diversificação dos métodos educacionais. O uso dos smartphones nas escolas deve ser planejado e inserido na interdisciplinaridade, não apenas pela direção escolar. Belloni (1999) diz que "tecnologia é um conjunto de discursos, práticas, valores e efeitos sociais ligados a uma técnica particular num campo particular" e se as TICs estão para auxiliar o professor nas técnicas de ensino-aprendizagem, portanto o professor assume o papel de supervisor em apontar qual recurso deve, quando e como utilizar.

Para que a informática penetre na escola e os alunos não se intitulem "sobreviventes" num meio o qual não lhes pertencem, é preciso que exista uma equipe de professores motivados, capazes de dedicar tempo ao projeto pedagógico e dispor de meios para adquirir e testar aplicativos. Esta equipe de educadores, intitulada "Diretoria de Inovação e Tecnologia Didática”, deve organizar-se para elaborar um projeto educativo, eficientemente interdisciplinar e otimizado. Estamos hoje em um ponto da história da educação onde a mudança radical está diretamente vinculada ao uso de dispositivos pessoais eletrônicos e o correto uso das TICs.

A informática na educação pode trazer inúmeros benefícios para o processo de ensinoaprendizagem, desde que o projeto tenha embasamento pedagógico e integre todas as áreas e todos os professores da escola. O smartphone deve ser um recurso adicional, não 
imposto pela sociedade e apelos de marketing. O professor deve lembrar que as ideias não saem do aparato tecnológico, mas de um projeto educativo global. Máquina não é a finalidade, é o artefacto para se alcançar objetivos pré-estabelecidos.

\section{Agradecimentos}

Projeto parcialmente financiado com recursos do Conselho Nacional de Desenvolvimento Científico e Tecnológico (CNPq), da Fundação de Amparo à Pesquisa do Estado de Minas Gerais (FAPEMIG) e do Centro Universitário do Leste de Minas Gerais (UnilesteMG). Também a Fundação Araucária, Secretaria de Estado da Ciência, Tecnologia e Ensino Superior (SETI-PR), ao Governo do Estado do Paraná e Universidade Tecnológica Federal do Paraná - UTFPR - Francisco Beltrão, pelo apoio financeiro recebido para viabilizar esta participação e à FCT - Fundação para a Ciência e a Tecnologia de Portugal, Projeto PEst-UID/CEC/Ooo27/2015.

\section{Referências}

Bauer, M. W., \& Gaskell, G. (2002). Pesquisa Qualitativa com Texto, Imagen e Som (5th ed.). Petrópolis, Rio de Janeiro: Vozes.

Bossuet, G. (1985). O Computador na Escola: sistema Logo. Porto Alegre: Artes Médicas.

CAPES, \& CNPq. (2012). Table of Knowledge Areas - CAPES and CNPq. CAPES Institutional Website, 22. Retrieved from http://tinyurl.com/capes-TabeladeArea

Carvalho, L. F. de S. (2015). Utilização de Dispositivos Móveis na aprendizagem da Matemática. Retrieved from http://repositorio.uportu.pt/jspui/ bitstream/11328/1272/1/TMTICE 11.pdf

Cysneiros, P. G. (1990). Didática, prática de ensino e tecnologia educacional. Tecnologia Educacional, 19, 25-30.

Falcão, A. P., Leite, M., \& Tenório, M. (2014). Ferramenta de apoio ao ensino presencial utilizando gamificação e design de jogos. In Anais do SBIE (pp. 526-533).

FILATRO, A. (2010). Design instrucional contextualizado (3rd ed.). São Paulo: SENAC.

Google. (2015). Google for Education: poupe tempo e fique conectado. Retrieved December 18, 2015, from http://tinyurl.com/zhr3p9o/

IBGE. (2013). Acesso à internet e posse de telefone móvel celular para uso pessoal. Rio de Janeiro: IBGE.

Koll, M. de O. (2010). Vygotsky: Aprendizado e desenvolvimento: um processo sócio-histórico. Scipione.

Leite, M. D., Marczal, D., Krynski, E. M., Pimentel, A., Direne, A., \& Reinaldo, F. (2015). Otimizando o processo de Ensino e Aprendizagem com a Arquitetura para Desenvolvimento de Objetos de Aprendizagem - ADOA. In XXVI Simpósio Brasileiro de Informática na Educação (ISSN 2316-6533) (pp. 1002-1011). Maceió, BR: SBIE. http://doi.org/10.5753/cbie.sbie.2015.1002 
Neri De Souza, D., Neri De Souza, F., Alarcão, I., \& Moreira, A. (2015). Visão de Orientadores e Orientandos sobre o Software Online de Supervisão da Investigação -IARS @. RISTI - Revista Ibérica de Sistemas E Tecnologias de Informação, (E4), 66-78. http://doi.org/10.17013/risti.e4.66-78

O’Connell, T., Freed, G., Rothberg, M., \& Carl and Ruth Shapiro. (2010). Using Apple technology to support learning for students with sensory and learning disabilities. Family National Center for Accessible Media, 1-25.

Oliveira, A., \& Júnior, S. (2013). Formação de Professores e Tecnologias da Informação e Comunicação - TICs : uma relação necessária para o uso de recursos tecnológicos na educação, 11-13. ESUD 2013 - X Congresso Brasileiro de Ensino Superior a Distância, Belém/PA, 11 - 13 de junho de 2013.

Papert, S. (1985). Logo: computadores e educação. São Paulo: Brasiliense.

Piaget, J. (1976). A Equilibração das Estruturas Cognitivas - Problema Central do Desenvolviment. Rio de Janeiro: Zahar Editores. Retrieved from http://www. labiutil.inf.ufsc.br/wazlawick9.html

Reinaldo, F., Camacho, R., \& Reis, L. P. (2010). Arquitetura Híbrida das Teoria de Aprendizagem em Camadas Comportamentais para Ensino a Distância. In 40th IGIP International Symposium on Engineering Education (ISBN 978-85-8912087-6) (Vol. 1, pp. 820-824). Santos, SP: COPEC.

Reinaldo, F., Camacho, R., Reis, L. P., \& Magalhães, D. R. (2009). Fine-Tune Artificial Neural Networks Automatically. In N. Mastorakis, V. Mladenov, \& T. V. Kontargyri (Eds.), Proceedings of the European Computing Conference: Volume 1. Lecture Notes in Electrical Engineering. (ISBN-10: 0387848134. ISBN-13: 978-0387848136) (Volume 27, Vol. 27, pp. 39-43). inbook, Boston, MA: SpringerVerlag Berlin Heidelberg. http://doi.org/10.1007/978-0-387-84814-3_5

Rossini, C., \& Gonzalez, C. (2012). REA: o debate em política pública e as oportunidades para o mercado. Recursos Educacionais Abertos: práticas colaborativas políticas públicas.

Serra, R. (2014). Escolas, alunos e professores "não falam mesma língua” - BBC Brasil. Retrieved February 1, 2015, from http://tinyurl.com/serra-140820salasocial-eleico

Silva, I. G. de S. S., Leão, M. B. C., \& de Souza, F. N. (2015). Plataforma FlexQuest®: Uma estratégia didática para a promoção de flexibilidade cognitiva e interdisciplinaridade com recursos Web 2.0. RISTI - Revista Ibérica de Sistemas e Tecnologias de Informação, (E4), 35-49. http://doi.org/10.17013/risti.e4.35-49

Sternberg, R. J., \& Grigorenko, E. L. (2003). The Psychology of Abilities, Competencies, and Expertise. Cambridge University Press.

Tikhomirov, V., Dneprovskaya, N., \& Yankovskaya, E. (2015). Three Dimensions of Smart Education. In Smart Innovation, Systems and Technologies (Vol. 41, pp. 44-56). 
Vázquez, M. Y. G., Sexto, C. F., Rocha, Á., \& Aguilera, A. (2016). Mobile Phones and Psychosocial Therapies with Vulnerable People: a First State of the Art. Journal of medical systems, 4O(6), 1-12. Doi: 10.1007/s10916-016-0500-y

West, M., \& Vosloo, S. (2013). UNESCO Policy guidelines for mobile learning. 